\title{
O PROCESSO DE LUTO EM POPULAÇÕES DE RISCO
}

\author{
Isabela Garcia Rosa Hispagnol 1 \\ Cibele Martins de Oliveira Marras ${ }^{2}$ \\ 1.Cofundadora do Percurso Instituto de Psicologia, Barueri, São Paulo \\ 2.Cofundadora do Percurso Instituto de Psicologia, Barueri, São Paulo \\ isabelahispagnol@percursoinstituto.com.br
}

\section{Introdução}

Este artigo é fruto de uma palestra proferida na V Jornada de Psicologia no Hospital Municipal do Campo Limpo, São Paulo, Brasil, em nove de outubro de dois mil e quatorze. $\mathrm{O}$ trabalho objetivou refletir junto a outros profissionais de saúde a experiência de perdas na infância, considerando ainda algumas situações como: abandono e o adoecimento.

O ser humano é um ser social. As crianças desde que nascem estão inseridas em um contexto social, e é nele que se desenvolvem e aprendem sobre o mundo, construindo sua forma de se relacionar e a visão acerca de si. Assim, neste contexto vivenciam as mais diversas situações e sentimentos relacionados, incluindo a dor pela separação e perda de um ente querido, o adoecimento e suas conseqüências, situações de desastres e catástrofes, abandono, entre outras.

A importância de olhar para as questões da infância, especialmente àquelas relativas a separações e perdas teve seu ápice apos a segunda guerra mundial, devido ao aumento de órfãos e a necessidade das mulheres em se inserirem no mercado de trabalho e na reconstrução da Europa, o que fez com que muitas crianças também tivessem que se separar de suas mães. John Bowlby (1907-1990), um psiquiatra londrino, iniciou um trabalho para entender os efeitos das separações, tanto temporárias como permanentes, na vida de bebes e crianças. Construiu então sua teoria que foi denominada Teoria do Apego, e demonstrou o quão importante os vínculos entre o bebê

\footnotetext{
Referência:

Hispagnol, Isabela Garcia Rosa; Marras, Cibele Martins de Oliveira. O Processo de Luto em Populações de Risco. In: Anais da V Jornada de Psicologia no Hospital Municipal do Campo Limpo [= Blucher Medical Proceedings, vol.1, num.6]. São Paulo: Editora Blucher, 2015.

DOI 10.5151/medpro-5jphmcl-002
} 
e seu cuidador são para a sobrevivência física e psíquica e para o desenvolvimento da personalidade.

Bowlby (2004 [1973]) observou que as perdas na infância, sob determinadas condições relativas aos acontecimentos pré e pós perda, levavam a uma maior incidência de transtornos psiquiátricos na vida adulta.

Ao considerarmos as situações expostas acima pensamos que, além do fato destas crianças estarem passando por um processo de luto, situação em si que as leva a uma condição maior de vulnerabilidade a problemas físicos e emocionais (a depender das circunstâncias, como veremos mais adiante), estas possuem outros agravantes que precisamos estar atentos.

\section{O Processo de Luto}

O luto é uma necessidade psicológica normal e esperada para que possamos elaborar as perdas significativas em nossas vidas. O processo de elaboração do luto é um trabalho de transição para nos adaptarmos às mudanças impostas pela perda nas mais diversas áreas de nossa vida, e que implica na transformação da relação com o falecido e com o que foi perdido, por meio da construção de novos significados.

Quando falamos em perdas, não nos referimos necessariamente à morte. Autores como Boss (2001), Kovács (1992) e Parkes (1998 [1996]), apontam outras vivências de perda: a separação entre vivos, situações de doença, o próprio desenvolvimento humano como formas de evolução - cujo curso é feito de perdas e ganhos - , a morte psíquica, amputações, a perda de uma casa, entre outras tantas possibilidades. Estas vivências despertam sentimentos de angústia, solidão, medo, dor, tristeza, sendo necessário, para o enfrentamento delas, um processo de elaboração, que chamamos de processo de luto. (Freud, 1974 [1915]; Bowlby, 2004 [1973]; Parkes, 1998 [1996])

A perda de alguém significativo abala o mundo que conhecemos e impõe mudanças na nossa realidade. Podemos nos sentir perdidos e ameaçados, uma vez que nosso mundo conhecido é, por vezes, desafiado, nos obrigando a rever nossas suposições e crenças acerca deste e que até então nos dava segurança. Como bem nos aponta Parkes (1993), qualquer mudança importante, seja ela percebida como positiva ou negativa, obriga o indivíduo a reestruturar seu entendimento de mundo. 
E isto não é diferente com as crianças mas, apesar de estarmos cientes da dor e tristeza que uma perda significativa provoca em cada um nós, este ainda é um assunto pouco discutido com as crianças, mesmo quando estas estão diretamente envolvida na situação. Podemos levantar algumas hipóteses da razão pela qual isto acontece. Monroe (2001) discorre sobre o medo do adulto em dizer ou fazer algo errado, que possa piorar a situação para a criança, causando-lhe ainda mais sofrimento e danos emocionais. Torres (2002, [1999]) fala da dificuldade do adulto em lidar com o tema da morte, já que isto faz com que ele tenha que necessariamente se confrontar com sua mortalidade. Na nossa prática vemos a dificuldade dos pais em conversar com a criança por não saber o que de fato ela compreende e como compreende, sentem-se confusos com as perguntas que apontam para uma outra forma de ver o mundo, como por exemplo " mas ele não pode voltar somente no meu aniversario?" Ou ainda “ah mas se eu pedir muito forte, Deus deixa ele vir só um pouquinho..."

\subsection{0 pesar e o luto na infância}

Uma questão de extrema importância é aquela que questiona se as crianças podem compreender a morte, se sentem pesar e se enlutam. É somente a partir dessa pergunta inicial que poderemos pensar como o processo de luto se dá em crianças e de que forma poderemos ajudá-las.

Para iniciarmos tal reflexão, consideramos que, para que uma pessoa sinta pesar e se enlute pela perda de alguém, é necessário a existência de um forte vínculo entre elas. É a partir da ruptura deste vínculo - e temos a morte como um dos motivos pelo qual isto acontece, porém não o único, como vimos anteriormente - e pela consciência da falta da pessoa amada, que se faz necessário o processo de luto para a elaboração desta perda e adaptação à nova realidade imposta.

Bowlby (2004 [1973]) observou que muitas crianças de 16 meses já podem reter na memória seu modelo do progenitor ausente, que pode ser acessado de tempos em tempos quando estão com pessoas desconhecidas. Desta forma, a criança, a partir desta idade, reluta em abrir mão de sua figura preferida, distinguindo-a de outras figuras, o que para ele já seriam razões para "atribuir uma capacidade germinal de luto a crianças pequenas" (idem, p. 511). 
Mas qual é a maneira pela qual as crianças vivenciam o processo de luto e quais fatores influenciam neste processo?

Bowlby (2004 [1973]) defende que a forma como as crianças sentem pesar se assemelha à forma como os adultos o fazem, porém, há um risco muito maior em crianças de desenvolver reações de luto complicado, devido a suas limitações na compreensão e o que lhes foi permitido saber, e a depender da condição de cuidados providas após a perda. Assim a criança está mais suscetível ao processo do adulto, uma vez que dele depende, principalmente para confortá-la e responder às suas angustias e ajudá-la com sua saudade.

Outros problemas são provocados pelo fato de a criança ter um entendimento menor de questões relacionadas à vida e à morte, estando mais sujeitas a tirar falsas conclusões das informações que recebem e entenderem erroneamente o significado dos acontecimentos que presenciam e das observações que ouvem. (Bowlby, 2004 [1973])

Para Worden (1996), o enlutar-se da criança, definido como o processo de adaptação da perda, consistiria nas mesmas tarefas dos adultos, porém estas devem ser entendidas considerando-se o desenvolvimento cognitivo, emocional e social da criança em questão, que é experimentada e expressa de forma diferente, segundo o momento de seu desenvolvimento.

Em linhas gerais, as tarefas psíquicas do enlutado são: aceitar a realidade da perda; elaborar a dor e outros sentimentos que aparecerem; ajustar-se ao mundo com as mudanças que ocorreram em decorrência desta perda; internalizar e ressignificar a relação com o que foi perdido; e dar continuidade a sua vida. Lembrando sempre que o processo é único para cada pessoa e caminhará de forma diversa dependendo de vários fatores, mesmo que todas as pessoas envolvidas tenham perdas semelhantes ou ainda que tenham perdido a mesma pessoa, ou vivam a mesma situação (como no caso do adoecimento, por exemplo).

\subsection{Especificidades do luto infantil}

Entendemos que a criança pode elaborar uma perda de forma semelhante ao adulto, independentemente do fato de ela estar em desenvolvimento de seu psiquismo. Estamos cientes que as reações comportamentais e os sintomas podem diferir dos adultos, assim 
como os meios para suprir suas necessidades, como por exemplo, as perguntas que irá fazer e os medos que terá, porém, talvez isso não implique que a elaboração se dê de forma distinta ou, ainda, que ela só seja capaz de elaborar mais à frente em seu desenvolvimento. A esse respeito nos indagamos se o fato de a criança compreender e significar a perda de forma diferente ao longo de seu desenvolvimento não seria o próprio ato de significar, algo que o adulto também faz ao longo de toda a sua vida e que, talvez, não necessariamente seja uma não elaboração. (Hispagnol, 2011)

Porém temos de estar atentos as variáveis que influenciam o processo de luto da criança e como podem atuar como fatores de risco ou de proteção.

As variáveis que influenciam o curso seguido pelo luto na infância são: (1) as causas e circunstâncias da perda, com especial referência àquilo que se diz à criança e que oportunidades lhe são dadas para indagar sobre o que aconteceu; (2) as relações da família após a perda, com especial referência à permanência da criança com o genitor sobrevivente e, caso isso ocorra, como se modificaram os padrões de relação em consequência da perda; (3) os padrões de relação dentro da família antes da perda, com especial referência aos padrões predominantes entre os pais e entre cada um deles e a criança enlutada; (4) influências familiares, como tamanho da família, padrão de comunicação, mudanças práticas; (5) suporte de iguais e outras pessoas fora da família; (6) características individuais da criança: idade, gênero, experiências passadas entre outras. (Bowlby, 2004 [1973]; Monroe, 2001)

\subsection{Reações e Sintomas}

Algumas respostas que podemos encontrar na criança enlutada:

- Acadêmicas: inabilidade em se concentrar; queda nas notas; dificuldade em completar tarefas ou ainda qualidade baixa nos trabalhos; ausências freqüentes ou relutância em ir à escola; esquecimentos freqüentes, perda de memória; performance aumentada, tentativa de perfeição; erros na fala ou ainda dificuldade em encontrar as palavras; falta de atenção; sonhar acordado.

- Comportamento: fazer muito barulho, comportamentos disruptivos; comportamentos agressivos, brigas freqüentes; não atender aos pedidos; atitudes de risco; comportamento "hiperativo"; isolamento e retraimento; 
comportamentos regressivos; grande necessidade de atenção; necessidade de checar como está o genitor sobrevivente.

- Emocional: insegurança, questões sobre abandono, preocupações com a segurança; preocupações em ser tratado de forma diferente dos outros; sentimentos de medo, culpa, raiva, ódio, arrependimento, tristeza e confusão; atitude de indiferença; depressão, desesperança, tristeza intensa; hiper sensibilidade, temeroso e irritado; preocupação com a morte, desejando detalhes; pensamentos recorrentes de morte e pensamentos suicida.

- Social: retraimento com os amigos; retraimento de atividades ou esportes; uso de drogas e/ou álcool; mudanças no relacionamento com professores e colegas; mudanças nos papéis familiares (como por exemplo, assumir o lugar do genitor falecido); querer ficar próximo fisicamente dos adultos; atitudes sexualizadas; praticar furtos e roubos; dificuldade de estar em grupo ou em meio a multidão.

- Físico: dores de estômago, de cabeça e no coração; acidentes mais freqüentes ou machucados; aumento nas visitas à enfermaria; pesadelos e dificuldade para dormir; perda ou aumento de apetite; baixa energia, fraqueza; alergias, coceiras; náusea; aumento de doenças, baixa resistência estando mais propicio à gripes e resfriados; coração acelerado.

- Espiritual: raiva de Deus; questionamentos como "Por que eu?"e "Por que agora?”; perguntas sobre o sentido da vida; confusões sobre onde está a pessoa que faleceu; sentimentos de solidão; duvidar e questionar crenças prévias; falta de sentido no futuro; mudança nos valores, questionando-se sobre o que é importante.

Bebês e crianças pequenas não possuem repertório verbal elaborado, porém expressam seu pesar através de comportamentos e brincadeiras como: ansiedade generalizada, choro, falta de sono, sono excessivo, problemas estomacais, ansiedade de separação, morder, jogar objetos, regressão a comportamentos que já haviam acabado (como por exemplo urinar na cama), irritabilidade, mudanças de temperamento. 


\subsection{Situações Especiais}

Duas situações em particular foram discutidas devido as particularidades que concernem às perdas envolvidas: $\mathrm{o}$ abrigamento $\mathrm{e} \mathrm{o}$ adoecimento.

As crianças abrigadas possuem um cenário complexo ao pensarmos sobre seu processo de luto pela separação dos pais e/ou cuidadores informais (familiares) e formais (funcionários do abrigo). Estas crianças foram abandonadas concretamente pela sua família de origem, ou então estavam sendo pouco cuidadas por estas. Seja um abandono real ou pelo descuido, há uma percepção da criança acerca disso. No processo de separação, muitas vezes, não há uma preparação para o afastamento, e mesmo dentro de condições precárias, a criança possui vínculos com esses cuidadores, e que são rompidos drasticamente.

A criança abrigada não sofre apenas a perda de vínculos significativos em sua vida, mas também tem sua identidade alterada. Ela não é mais a filha mais velha, ou a neta. Agora ela é uma criança no abrigo. A perda da casa, que também exerce um papel importante na nossa construção de mundo, é outra perda significativa para essa criança. A casa é o lar, mesmo que não seja adequado. É o local que nos sentimos seguros, onde construímos nossas primeiras relações e onde vivemos nossas primeiras memórias. Há ainda a perda da comunidade onde a criança está inserida, como a escola, os amigos, o bairro, e todas essas perdas podem ser disparadores para um luto. Assim, a criança abrigada sofre múltiplas perdas e terá muitos lutos. (Tinoco, 2007)

Ainda podem apresentar um histórico de violência doméstica, trazendo marcas emocionais importantes decorrentes desse abuso, podendo potencializar algumas reações emocionais advindas do abrigamento. Muitas vezes, o luto se dá pela separação do cuidador formal, e não só o da família. Esse luto, assim como outros que são sentidos pelas crianças (em especial pela visão de que ela saiu de uma situação ruim), não são facilmente reconhecidos pelos adultos, podendo levá-la a não ter suas reais necessidades atendidas.

Outra situação que merece nossa atenção é a que se refere ao adoecimento. $\mathrm{O}$ adoecimento é um momento que demanda muitos cuidados físicos, mas também é preciso cuidados emocionais. Dependendo da gravidade da situação, no processo de adoecimento ocorrem muitas perdas, e portanto há uma série de lutos a serem elaborados. O mais evidente é o luto pela perda da saúde, da condição de saudável e de 
atividades que antes eram permitidas e não são mais. $\mathrm{O}$ entendimento da criança sobre sua condição de saúde também dependerá de seu desenvolvimento intelectual.

Crianças hospitalizadas sofrem pelas restrições, por estarem longe de seus amigos, de sua casa, de sua escola e de sua comunidade como um todo. Esses rompimentos podem desencadear um luto. Além disso, elas também convivem diariamente com a dor e o sofrimento. São submetidas a procedimentos e não podem manter sua própria identidade, como usar o seu pijama, ficar com seu ursinho de pelúcia preferido, questões estas que tem sido debatidas para uma maior flexibilização.

A família da criança doente também merece atenção. A hospitalização traz consigo um pensar na morte, na possibilidade de perda dessa criança, o que pode gerar sentimentos e reações intensas nos adultos cuidadores, que influenciarão seus comportamentos com a criança. Cuidar do luto do adulto pode ajudar a criança com o seu próprio luto.

\section{Considerações Finais}

Trabalhar com crianças enlutas e suas famílias é um desafio para o profissional de saúde. É um trabalho um tanto quanto gratificante porém muitas vezes difícil, e que exige do profissional conhecimento, sensibilidade e disponibilidade. Para os que estão na área, é imprescindível o autocuidado, a troca com outros profissionais e o aprimoramento constante.

É importante sempre lembrar que a perda é única para cada pessoa e envolve diversos fatores, dos quais muitas vezes não temos conhecimento ou acesso imediato, porém, ao desenvolvermos uma postura empática e de abertura, é possível olhar para aquele que sofre e efetivamente ter ações para ajudá-lo.

Ao nos aproximarmos da vivencia de luto da criança em situação de vulnerabilidade e entendermos os fatores de risco e de proteção podemos ajudar a promover competência sempre.

\section{Referências Bibliográficas:}

1. BOSS, P. La perdida ambigua: cómo aprender a vivir con un duelo no terminado. Barcelona: Gedisa, 2001. 
2. BOWLBY, J. (1973). Perda: tristeza e depressão. In: Apego e Perda, v. 3. São Paulo: Editora Martins Fontes, 2004.

3. FREUD, S. (1915). Luto e melancolia. In: Obras completas. Rio de Janeiro: Imago, 1974.

4. HISPAGNOL, I.G.R. O luto infantil e a construção de significados familiares frente à morte de um ente querido. Dissertação (Mestrado em Psicologia). Faculdade de Psicologia, Pontifícia Universidade Católica de São Paulo, 2011.

5. KOVÁCS, M. J. Morte, separação, perdas e o processo de luto. In: KOVÁCS, M. J. (Org.). Morte e desenvolvimento humano. São Paulo: Casa do Psicólogo, 1992. p.149-264.

6. MONROE, B. Children and Bereavement. Workbook 4 Bereavement: Private Grief and Collective Responsibility. London, 2001.

7. PARKES, C.M. (1996). Luto: estudos sobre a perda na vida adulta. São Paulo: Summus Editorial, 1998.

8. Bereavement as a psychosocial transition: processes of adaptation to change. In:

9. STROEBE, M. S.; STROEBE, W.; HANSSON, R. O. Handbook of bereavement: theory, research and intervention. Cambridge: University Press, Nova Iorque, 1993.

10.TINOCO, V. O luto em instituições de abrigamento: um desafio para cuidadores temporários. Tese de Doutorado. São Paulo: PUC-SP, 2007.

11.TORRES, W. C. (1999) A criança diante da morte. São Paulo: Casa do Psicólogo, 2002.

12.WORDEN, J. W. Children and grief: when a parent dies. Guilford Press, Nova Iorque, 1996. 